\title{
Correlação e análise de trilha para componentes de produção de milho superdoce ${ }^{1}$
}

\author{
Geovana Cremonini Entringer', Pedro Henrique Araújo Diniz Santos², Julio Cesar Fiorio Vettorazzi ${ }^{3}$, \\ Keila Silva da Cunha ${ }^{4}$, Messias Gonzaga Pereira
}

\section{RESUMO}

Em programas de melhoramento genético, informações sobre a correlação entre caracteres são de grande importância para se aperfeiçoar a seleção simultânea de caracteres. Contudo, a quantificação e a interpretação da magnitude de uma correlação podem resultar em equívocos na estratégia de seleção. O objetivo deste trabalho foi avaliar, por meio da análise de trilha, as relações, direta e indireta, entre os componentes primários de produção e a produtividade de espiga de milho superdoce, e identificar os caracteres que mais contribuem para a produtividade de espiga (variável básica). Verifica-se que as variáveis utilizadas explicaram $94,77 \%$ da variação do peso de espiga $\left(\mathrm{R}^{2}\right)$. Pela análise de trilha, apenas dois caracteres, o volume do grão $(0,2637)$ e o volume de espiga $(0,2536)$, apresentaram efeito direto na produção. Constata-se, portanto, que, apesar de a maioria dos caracteres apresentarem altas estimativas de correlação, essas ocorreram por efeitos indiretos de outros caracteres. Assim, tanto para seleção direta, quanto para seleção indireta, essas características são eficientes no aumento do peso médio da espiga de milho superdoce. Neste caso, a melhor estratégia seria a seleção simultânea de caracteres, enfatizando-se as características cujos efeitos indiretos são maiores. É oportuno salientar que o volume de grão e volume de espiga apresentaram maiores herdabilidades, quando comparados com peso de espigas, ou seja, $91,92,88,6$ e 80,52\%, respectivamente. A alta herdabilidade estimada ( 91,92 e $88,6 \%$ ) é um indicativo de possibilidades de elevados ganhos genéticos na seleção.

Palavras-chave: coeficiente de trilha, efeitos diretos e indiretos, resposta correlacionada.

\begin{abstract}
Correlation and path analysis for yield components of supersweet corn

In breeding programs, information on the correlation between characters is essential to improve the simultaneous selection of characters. However, the measurement and interpretation of the magnitude of a correlation can lead to mistakes in the selection strategy. The objective of this study was to evaluate, using path analysis, the direct and indirect components between primary production and yield of supersweet corn ear and identify the characteristics that most contribute to ear yield (basic variable). The variables used explained $94.77 \%$ of the variance in ear weight $\left(R_{2}\right)$. The path analysis showed that only two characters, grain volume (0.2637) and ear volume (0.2536), had a direct effect on production. It appears, therefore, that although the majority of the characters present high correlation estimates, these
\end{abstract}

\footnotetext{
Recebido para publicação em 29/01/2013 e aprovado em 26/08/2013.

Este trabalho é parte do projeto de tese da primeira autora.

Engenheira-Agrônoma, Mestre. Laboratório de Genética e Melhoramento de Plantas, Universidade Estadual do Norte Fluminense Darcy Ribeiro, Campus dos Goytacazes, Avenida Alberto Lamego, 2000, 28013-602, Campos dos Goytacazes, Rio de Janeiro, Brasil. geocremonini@yahoo.com.br (autora para correspondência).

${ }^{2}$ Engenheiro-Agrônomo, Mestre. Laboratório de Genética e Melhoramento de Plantas, Universidade Estadual do Norte Fluminense Darcy Ribeiro, Campus dos Goytacazes, Avenida Alberto Lamego, 2000, 28013-602, Campos dos Goytacazes, Rio de Janeiro, Brasil. phsantos2004@ yahoo.com.br

${ }^{3}$ Graduando em Agronomia. Laboratório de Genética e Melhoramento de Plantas, Universidade Estadual do Norte Fluminense Darcy Ribeiro, Campus dos Goytacazes, Avenida Alberto Lamego, 2000, 28013-602, Campos dos Goytacazes, Rio de Janeiro, Brasil. juliocesar.f.v@ hotmail.com

${ }^{4}$ Engenheira-Agrônoma, Mestre. Laboratório de Genética e Melhoramento de Plantas, Universidade Estadual do Norte Fluminense Darcy Ribeiro, Campus dos Goytacazes, Avenida Alberto Lamego, 2000, 28013-602, Campos dos Goytacazes, Rio de Janeiro, Brasil. kscuenf@ hotmail.com

5 Engenheiro-Agrônomo, Doutor. Laboratório de Genética e Melhoramento de Plantas, Universidade Estadual do Norte Fluminense Darcy Ribeiro, Campus dos Goytacazes, Avenida Alberto Lamego, 2000, 28013-602, Campos dos Goytacazes, Rio de Janeiro, Brasil. messias@uenf.br
} 
indirect effects were due to other characters. Thus, for both direct selection and indirect selection for such characters are effective in increasing the average weight of supersweet corn ear. In this case, the best strategy would be the simultaneous selection of characters, emphasizing the characteristics whose effects are more indirect. It should be noted that grain volume and ear volume had higher heritability than ear weight, i.e., $91.92 \%, 88.6 \%$ and $80.52 \%$ respectively. The high heritability estimates $(91.92 \%$ and $88.6 \%)$ is an indication of possible high gains in genetic selection.

Key words: path coefficients, direct and indirect effects, correlated response.

\section{INTRODUÇÃO}

A exploração comercial do milho superdoce passa pelo melhoramento genético da cultura, o que demanda a avaliação da resposta de cultivares às condições do ambiente, à variabilidade entre e dentro do germoplasma em questão e, sobretudo, à seleção de genótipos superiores para características morfoagronômicas de interesse (Lopes et al., 2007).

Para o melhoramento genético de plantas, a escolha de um método de seleção que favoreça a identificação de genótipos superiores é a etapa de maior importância na obtenção de novos cultivares. Diante disto, o conhecimento das correlações entre caracteres permite traçar estratégias alternativas para maximizar o ganho previsto com a seleção de vários caracteres, simultaneamente, ou alavancar os ganhos genéticos de um caráter que apresenta baixa herdabilidade e, ou, dificuldades de mensuração. Nestes casos, a seleção indireta pode ser mais efetiva que a direta, ao selecionar um caráter com alta herdabilidade, de fácil mensuração, de fácil identificação e que apresenta alta correlação com o caráter desejado (Falconer \& Mackay, 1996).

A ocorrência de correlação genética entre dois caracteres pode ser devida à pleiotropia ou à ligação gênica. A correlação entre caracteres pode assumir um valor positivo, negativo ou nulo. Vale salientar que a ligação gênica só é causa de correlação em populações em desequilíbrio de ligação (Falconer, 1996).

Embora tenha grande utilidade para o melhoramento de plantas, o estudo de correlação pode causar equívocos na estratégia de seleção, pois uma correlação alta entre dois caracteres pode ser resultado do efeito de um terceiro, ou de um grupo de outros caracteres (Cruz \& Regazzi, 1997). A fim de melhor se conhecer as causas e efeitos envolvidos nas associações entre caracteres, Wright (1921) propôs um método denominado de análise de trilha, ou "Path analyis", que desdobra as correlações estimadas em efeitos diretos e indiretos de caracteres, sobre uma variável básica, ou principal.
A produtividade da espiga do milho superdoce é um caráter complexo, ou seja, influenciado por vários componentes, a saber: o peso médio de espiga, o comprimento médio das espigas, o diâmetro médio do sabugo, o diâmetro médio de espigas, o comprimento do grão, dentre outras. A identificação de componentes de produção de espigas, que apresentem maior contribuição sobre a produtividade da espiga, é interessante e pode auxiliar na seleção de genótipos superiores (Lopes et al., 2007).

Sabe-se que as culturas dos milhos doce e superdoce têm alcançado altos níveis de produtividade. Essa evolução deve-se aos crescentes estudos realizados em diversas áreas e, sobretudo, ao melhoramento genético.

O objetivo deste trabalho foi verificar, por meio da análise de trilha, as relações direta e indireta, entre os componentes do rendimento, e identificar qual apresenta maior contribuição na produtividade em genótipos de milho superdoce.

\section{MATERIAIS E MÉTODOS}

Foram utilizadas progênies de retrocruzamentos, tendo como genitores doadores do caráter superdoce, obtidos pelo Centro Nacional de Pesquisa em Milho e Sorgo (CNPMS), ambos portadores do gene shrunken-2 (sh2), a saber: superdoce sintético $\mathrm{SH}_{2}(\mathrm{SH})$ e o superdoce sintético $\mathrm{SH}_{2}-8 \mathrm{HS}$ (SH-8HS) e, como genitores recorrentes, as populações CIMMYT8 e Piranão8. Os recorrentes são oriundos do oitavo ciclo de seleção recorrente recíproca de famílias de irmãos completos, da Universidade Estadual do Norte Fluminense Darcy Ribeiro (UENF).

Os genótipos doadores foram cruzados com os recorrentes e, posteriormente, as progênies obtidas retrocruzadas até a recuperação de, ao menos, $98 \%$ dos genes provenientes dos genitores recorrentes, resultando, assim, em quatro populações de milho, com endosperma superdoce, com características morfoagronômicas superiores, a saber: CIMMYT8, retrocruzado com SH (CSH); CIMMYT8, retrocruzado com SH-8SHS (CSH-8HS); Piranão8, retrocruzado com SH (PSH); Piranão8, 
retrocruzado com SH-8SHS (PSH-8HS). Essas populações foram utilizadas como genitores para obter os seguintes híbridos interpopulacionais: PSH x CSH; PSH x CSH-8HS; PSH-8HS x CSH-8HS; PSH-8HS x CSH, de modo que todos os genótipos de milho com endosperma superdoce, mencionados anteriormente, foram utilizados como tratamentos nas avaliações. Foram avaliados dez genótipos de milho doce, entre híbridos e variedades de polinização aberta.

O ensaio foi realizado de agosto a novembro de 2010 , em delineamento experimental de blocos ao acaso, com quatro repetições, na estação experimental do Colégio Agrícola Antônio Sarlo, município de Campos dos Goytacazes, RJ. Cada parcela experimental foi composta por duas linhas de $5 \mathrm{~m}$, com espaçamento de $0,3 \mathrm{~m}$ entre plantas e $1 \mathrm{~m}$ entre fileiras. Foram utilizadas quatro linhas contínuas, em torno da área de plantio, como bordadura. Na semeadura, foram distribuídas seis sementes por cova, com posterior desbaste para uma planta por cova, aos 30 dias após a semeadura.

Foi feita adubação de semeadura, com adubo químico de fórmula 8-28-16, na dose de $400 \mathrm{~kg}$.ha-1 ${ }^{-1}$, e uma adubação em cobertura, com 20 gramas de ureia por metro linear, aos 20 e aos 40 dias pós- semeadura. As plantas dos genótipos de milho comum foram emasculadas no final do estádio VT, a fim de evitar a ocorrência de efeito xênia. As irrigações, bem como os demais tratos culturais, deram-se de acordo com as recomendações para a cultura do milho (Fancelli \& Dourado Neto, 1999).

As avaliações foram realizadas entre os estádios $\mathrm{R} 4 \mathrm{e}$ R5, com a espiga de milho verde, aos 22 dias após a polinização. As características avaliadas foram: peso médio de espiga (PE); comprimento médio das espigas (CE); diâmetro médio do sabugo (DS); diâmetro médio de espigas (DE); comprimento do grão (CG); volume da espiga (VE); volume do sabugo (VS); volume de grãos (VG); número de fileiras de grãos (NFG). Para cada caráter foram avaliadas, aleatoriamente, dez espigas por parcela.

Com o objetivo de comparar os efeitos dos genótipos e estimar a herdabilidade com base na média, procedeu-se à análise de variância. Estimaram-se, também, coeficientes de correlação de Pearson (Stell et al., 1997), entre as nove características componentes da produção avaliadas.

Antes de se realizar a análise de trilha, a matriz de correlação fenotípica foi testada, quanto à multicolinearidade, pelo número de condição da matriz (NC), proposto por Montgomery e Peck (1981), que consiste na razão do maior pelo menor autovalor da matriz. Em presença de multicolinearidade moderada $(100<\mathrm{NC}<1000)$, ou severa (NC>1000), os coeficientes de caminhamento estimados não são confiáveis, em função das elevadas variâncias associadas aos seus estimadores (Carvalho \& Cruz, 1996).No entanto, em presença de multicolinearidade fraca (NC < 100), não há problemas quanto à confiabilidade dos coeficientes de caminhamento.

Sobre a matriz das correlações entre as nove características, procedeu-se ao diagnóstico de multicolinearidade, pelo número de condição (NC), proposto por Montgomery \& Peck (1981).

Em seguida, as correlações das demais variáveis e a variável PE (variável dependente) foram desdobradas em efeitos diretos e indiretos, pela análise de trilha, com uma cadeia, estabelecendo-se as relações de causa e efeito entre as características, conforme descrito por Cruz, Regazzi \& Carneiro (2004).

Todas as análises foram realizadas com o programa computacional Genes (CRUZ, 2009).

\section{RESULTADOS E DISCUSSÃO}

Genótipos de milho superdoce diferiram estatisticamente $(\mathrm{p}<0,01)$, para todos os caracteres, exceto para DS, o que evidencia a presença de variabilidade nas populações estudadas. Pode-se inferir que o experimento teve precisão experimental dentro da normalidade, com coeficientes de variação oscilando entre $2,95 \%$, para NFG, e $9,24 \%$, para CG, de acordo com a classificação proposta por Scapin et al. (1995) (Tabela 1).

Na Tabela 2, encontram-se as estimativas das correlações de Pearson entre as características avaliadas. $\mathrm{O}$ peso médio de espiga (PE) foi fortemente correlacionado, positivamente, com seis das oito variáveis explicativas observadas, com estimativas de correlação entre 0,7775 (VS e PE) e 0,9686(VE e PE). Pode-se inferir, ainda, que na maioria, as variáveis explicativas correlacionam-se positivamente entre si, mostrando a complexidade da relação entres as características que influenciam PE.

A variável NFG está correlacionada negativamente com CE (-0,6514) e com VG (-0,6798). Este resultado pode ser explicado quando se verificam as altas e positivas correlações entre CG e VG $(0,9110)$ e CG e PE $(0,8021)$ e que ambos os caracteres (CG e VG) correlacionam-se negativamente com NFG. Essas estimativas apontam que o aumento do CG é diretamente proporcional ao incremento do VG e do PE. Sendo assim, à medida que os tamanhos do grão (VG e CG) e da espiga aumentam, há redução do NFG.

Vista a complexidade entre os componentes da produção que contribuem para o PE, a seleção de genótipos de milho superdoce é dificultada. Deste modo, fica evidente a necessidade do desdobramento das correlações, em efeitos diretos e indiretos, para avaliar-se o grau de importância de cada uma das variáveis explicativas em relação à variável principal ou básica (Daros et al., 2004).

Para maior confiabilidade dos resultados da análise de trilha, a matriz de correlação fenotípica entre os caracteres 
foi testada, quanto à multicolinearidade, pelo número de condições proposto por Montgomery e Peck (1981). A matriz de correlação apresentou multicolinearidade severa $(\mathrm{NC}=504565,82)$. Para contornar esse problema, foi utilizada a metodologia proposta por Carvalho \& Cruz (1996), que consiste em aplicar uma constante $\mathrm{k}$ na diagonal da matriz X'X do estimador de mínimos quadrados ordinários. O valor k aplicado foi de 4,8756, tornando os resultados apresentados confiáveis.

Os coeficientes de trilha, das variáveis consideradas como primárias, encontram-se na Tabela 3. Verifica-se que as variáveis utilizadas explicaram $94,77 \%$ da variação total do $\mathrm{PE}\left(\mathrm{R}^{2}\right)$. Pela análise de trilha, apenas dois caracteres apresentaram efeito direto na produção de milho superdoce, VG $(0,2637)$ e VE $(0,2536)$, por apresentarem efeitos diretos superiores à variável residual. Ambos são de equivalente importância, pois os efeitos indiretos de ambas as variáveis também foram elevados. Assim, essas duas variáveis podem favorecer o ganho em PE em um processo de seleção simultânea.

Os demais caracteres apresentaram efeito direto inferior à variável residual e suas associações podem não ser relevantes para PE (Cruz et al., 2004). Constata-se, por- tanto, que, apesar de a maioria dos caracteres apresentarem altas estimativas de correlação, essas ocorreram por efeitos indiretos de outros caracteres, por exemplo, a correlação de DE com PE ocorreu especialmente por efeitos indiretos de $\operatorname{VG}(0,2421)$ e do $\operatorname{VE}(0,2315)$.

Apesar de $75 \%$ das variáveis estudadas apresentarem correlações altas e positivas, apenas VE e VG apresentaram alguma influência sobre $\mathrm{PE}$, pois seus efeitos diretos foram superiores ao efeito da variável residual, sendo VG o caráter de maior efeito direto. Este resultado evidencia como o estudo de correlações pode levar ao erro, e também corrobora a afirmativa sobre quão importante é fazerse o desdobramento das correlações em efeitos diretos e indiretos. Assim, pode-se inferir que tanto a seleção direta, quanto a seleção indireta, dos caracteres VE e VG são eficientes no aumento do peso médio da espiga de milho superdoce. Neste caso, a melhor estratégia seria a seleção simultânea de caracteres, enfatizando-se as características cujos efeitos diretos são maiores.

Contudo, as características VE e VG apresentaram maiores valores de herdabilidades, quando comparados com PE, ou seja, 91,92, 88,6 e 80,52\% respectivamente. Os altos valores de herdabilidade estimados $(91,92$ e $88,6 \%)$

Tabela 1. Resumos das análises de variâncias referentes a comprimento médio das espigas (CE), diâmetro médio das espigas (DE), diâmetro médio dos sabugos (DS), comprimento médio do grão (CG), volume médio de espiga (VE), volume médio do sabugo (VS), número de fileiras de grãos (NFG) e peso médio de uma espiga (PE)

\begin{tabular}{|c|c|c|c|c|c|c|c|c|c|c|}
\hline \multirow{2}{*}{ F.V. } & \multirow{2}{*}{ GL } & \multicolumn{8}{|c|}{ Quadrados médios } & \multirow[b]{2}{*}{ PE } \\
\hline & & $\overline{\mathrm{CE}}$ & DE & DS & CG & $\mathbf{V E}$ & VS & VG & NFG & \\
\hline Bloco & 3 & 0,19 & 1,73 & 5,30 & 2,38 & 1073,18 & 2157,16 & 3582,68 & 0,08 & 55,51 \\
\hline Genótipos & 9 & $7,30 * *$ & $12,46 * *$ & 3,007 & $2,90 * *$ & $30890,53 * *$ & $6665,65 * *$ & $11460,70 * *$ & $7,24 * *$ & $2305,29 *$ \\
\hline Resíduo & 27 & 0,57 & 2,86 & 1,76 & 0,86 & 2497,07 & 1473,72 & 1306,51 & 0,14 & 402,60 \\
\hline Total & 39 & & & & & & & & & \\
\hline C.V. & & 3,81 & 3,63 & 5,02 & 9,24 & 5,94 & 7,33 & 9,02 & 2,95 & 9,11 \\
\hline $\mathrm{H}^{2}$ & & 92,19 & 77,01 & 41,36 & 70,07 & 91,92 & 77,89 & 88,6 & 97,98 & 80,52 \\
\hline DMS (5\%) & & 1,83 & 4,11 & 3,23 & 2,26 & 121,53 & 93,36 & 87,91 & 0,92 & 48,80 \\
\hline
\end{tabular}

** Significativos a $1 \%$ de probabilidade.

Tabela 2. Estimativas das correlações de Pearson entre comprimento de espiga (CE), diâmetro de espiga (DE), diâmetro de sabugo (DS), comprimento do grão (CG), volume da espiga (VE), volume do grão (VG), número de fileiras de grãos (NFG) e peso médio de uma espiga (PE) de dez genótipos de milho superdoce

\begin{tabular}{|c|c|c|c|c|c|c|c|c|c|}
\hline & $\mathbf{C E}$ & DE & DS & CG & $\mathbf{V E}$ & VS & VG & NFG & PE \\
\hline $\mathrm{CE}$ & 1 & 0,5993 & 0,0930 & 0,5795 & $0,9461 * *$ & $0,9494 * *$ & $0,8597 * *$ & $-0,6514 *$ & $0,7775 * *$ \\
\hline DE & & 1 & 0,3161 & $0,8753 * *$ & $0,8259 * *$ & $0,6600 *$ & $0,8525 * *$ & $-0,3969$ & $0,9316^{* *}$ \\
\hline DS & & & 1 & $-0,1820$ & 0,1990 & 0,4980 & $-0,0531$ & 0,3607 & 0,3212 \\
\hline $\mathrm{CG}$ & & & & 1 & $0,7551 * *$ & 0,4309 & $0,9110 * *$ & $-0,5954$ & $0,8021 * *$ \\
\hline $\mathrm{VE}$ & & & & & 1 & $0,9093 * *$ & $0,9483 * *$ & $-0,6130$ & $0,9686 * *$ \\
\hline VS & & & & & & 1 & $0.7302 *$ & $-0,4282$ & $0,7629 * *$ \\
\hline VG & & & & & & & 1 & $-0.6798^{*}$ & $0,9499 * *$ \\
\hline NFG & & & & & & & & 1 & $-0,4317$ \\
\hline PE & & & & & & & & & 1 \\
\hline
\end{tabular}

** $\mathrm{e}^{*}$ : Significativos a 1 e $5 \%$ de probabilidade pelo teste $\mathrm{t}$. 
permitem o uso de estratégias de seleção mais simples (Borém \& Miranda, 2005) e contribuem para maiores ganhos genéticos. Assim, o melhorista poderia selecionar genótipos com maior volume de espigas e volume de grão, que, indiretamente, estaria selecionando os que proporcionariam maior produtividade de espiga.

Tabela 3. Estimativas dos efeitos diretos e indiretos das variáveis consideradas como primárias sobre a variável principal peso médio de uma espiga (PE), realizadas com os dados de média de genótipos de milho superdoce

\begin{tabular}{|c|c|}
\hline Caracteres & Coeficiente de trilha \\
\hline \multicolumn{2}{|l|}{$\mathbf{C E}$} \\
\hline Efeito direto sobre PE & 0,0862 \\
\hline Efeito indireto via DE & 0,1137 \\
\hline Efeito indireto via DS & 0,0052 \\
\hline Efeito indireto via CG & 0,0957 \\
\hline Efeito indireto via VE & 0,2212 \\
\hline Efeito indireto via VS & 0,1017 \\
\hline Efeito indireto via VG & 0,2204 \\
\hline Efeito indireto via NFG & $-0,0711$ \\
\hline Total & 0,7775 \\
\hline \multicolumn{2}{|l|}{ DE } \\
\hline Efeito direto sobre PE & 0,1897 \\
\hline Efeito indireto via CE & 0,0517 \\
\hline Efeito indireto via DS & 0,0178 \\
\hline Efeito indireto via CG & 0,1458 \\
\hline Efeito indireto via VE & 0,2315 \\
\hline Efeito indireto via VS & 0,0869 \\
\hline Efeito indireto via VG & 0,2421 \\
\hline Efeito indireto via NFG & $-0,0433$ \\
\hline Total & 0,9316 \\
\hline \multicolumn{2}{|l|}{ DS } \\
\hline Efeito direto sobre PE & 0,0564 \\
\hline Efeito indireto via CE & 0,0080 \\
\hline Efeito indireto via DE & 0,0599 \\
\hline Efeito indireto via CG & $-0,0303$ \\
\hline Efeito indireto via VE & 0,0636 \\
\hline Efeito indireto via VS & 0,0977 \\
\hline Efeito indireto via VG & 0,0236 \\
\hline Efeito indireto via NFG & 0,0394 \\
\hline Total & 0,3212 \\
\hline \multicolumn{2}{|l|}{ CG } \\
\hline Efeito direto sobre PE & 0,1666 \\
\hline Efeito indireto via CE & 0,0495 \\
\hline Efeito indireto via DE & 0,1660 \\
\hline Efeito indireto via DS & $-0,0102$ \\
\hline Efeito indireto via VE & 0,2076 \\
\hline Efeito indireto via VS & 0,0403 \\
\hline Efeito indireto via VG & 0,2390 \\
\hline Efeito indireto via NFG & $-0,0650$ \\
\hline Total & 0,8021 \\
\hline
\end{tabular}

É importante salientar, também, que o sucesso da seleção é diretamente proporcional ao aumento da herdabilidade, ou seja, quanto maior for a estimativa da herdabilidade, maior será a probabilidade de se realizar uma seleção eficaz (Cruz et al., 2004). Neste trabalho, não se pretende enfatizar a dificuldade em se mensurar os compo-

Continuação...

\begin{tabular}{cc}
\hline Caracteres & Coeficiente de trilha \\
VE &
\end{tabular}

\begin{tabular}{ll}
\hline Efeito direto sobre PE & 0,2536 \\
Efeito indireto & 0,0752
\end{tabular}

Efeito indireto via $\mathrm{CE} \quad 0,0752$

Efeito indireto via DE $\quad 0,1732$

Efeito indireto via DS $\quad 0,0141$

Efeito indireto via CG $\quad 0,1363$

Efeito indireto via VS $\quad 0,1055$

Efeito indireto via VG $\quad 0,2591$

Efeito indireto via NFG $\quad-0,0612$

Total 0,9686

VS

Efeito direto sobre PE $\quad 0,1350$

Efeito indireto via CE $\quad 0,0650$

Efeito indireto via DE $\quad 0,1220$

Efeito indireto via DS $\quad 0,0408$

Efeito indireto via CG $\quad 0,0497$

Efeito indireto via VE $\quad 0,1982$

Efeito indireto via VG $\quad 0,1719$

Efeito indireto via NFG $\quad-0,0254$

\begin{tabular}{ll}
\hline Total & 0,7629 \\
\hline & VG
\end{tabular}

Efeito direto sobre PE $\quad 0,2637$

Efeito indireto via CE $\quad 0,0721$

Efeito indireto via DE $\quad 0,1741$

Efeito indireto via DS $\quad 0,0050$

Efeito indireto via CG $\quad 0,1509$

Efeito indireto via VE $\quad 0,2492$

Efeito indireto via VS $\quad 0,0880$

Efeito indireto via NFG $\quad-0,0668$

\begin{tabular}{ll}
\hline Total & 0,9499 \\
\hline & NFG
\end{tabular}

Efeito direto sobre $\mathrm{P}$

Efeito indireto via CE $\quad-0,0562$

Efeito indireto via DE $\quad-0,0753$

Efeito indireto via DS $\quad 0,0203$

Efeito indireto via CG $\quad-0,0991$

Efeito indireto via VE $\quad-0,1422$

Efeito indireto via VS $\quad-0,0315$

Efeito indireto via VG $\quad-0.1614$

Total $\quad-0,4317$

Coeficiente de determinação $\quad 0,9477$

\begin{tabular}{ll}
\hline Valor de K & 4,8756 \\
\hline Variável residual & 0,2285
\end{tabular}

Rev. Ceres, Viçosa, v. 61, n.3, p. 356-361, mai/jun, 2014 
nentes de produção da espiga do milho superdoce, mas, sim, propor aos melhoristas uma maior compreensão de como os componentes de produção influenciam, de forma direta, ou indiretamente, a produtividade de espigas, e, também, sugerir diferentes escolhas de variáveis, que poderão ser selecionadas a fim de se maximizar o ganho genético com a seleção.

\section{CONCLUSÕES}

As populações de milho superdoce apresentam variabilidade para os componentes de produção. As variáveis volume de espiga e volume de grãos são as que mais contribuem para o aumento do peso médio da espiga.

A seleção simultânea dessas características pode auxiliar o melhorista na seleção de genótipos superiores.

\section{AGRADECIMENTOS}

Os autores agradecem ao Técnico Agrícola Geraldo Francisco de Carvalho, pelo auxílio nos cruzamentos para obtenção dos genótipos utilizados neste experimento, e à Fundação Carlos Chagas Filho de Amparo à Pesquisa, do Estado do Rio de Janeiro (FAPERJ), pelo apoio financeiro.

\section{REFERÊNCIAS}

Borém A \& Miranda GV(2005) Melhoramento de plantas. $4^{\mathrm{a}}$ ed. Viçosa, UFV. 525p.

Carvalho SP \& Cruz CD (1996) Diagnosis of multicollinearity: assessment of the condition of correlation matrices used in genetic studies. Brazilian Journal of Genetics, 19:479-484.

Cruz CD \& Regazzi AJ (1997) Modelos biométricos aplicados ao melhoramento genético. $2^{a}$ ed. Viçosa, UFV. 390p

Cruz CD, Regazzi AJ \& Carneiro CS(2004) Modelos biométricos aplicados ao melhoramento genético. $3^{\mathrm{a}}$ ed. Viçosa, UFV. 479p.

Cruz CD (2009) Programa Genes: versão Windows - aplicativo computacional em genética e estatística. Viçosa, UFV. 648p.

Daros M, Amaral Júnior TA, Pereira MG, Santos SF, Scapim AC, Freitas Júnior PS, Daher FR \& Ávila MR (2004) Correlações entre caracteres agronômicos em dois ciclos de seleção recorrente em milho de pipoca. Ciência Rural, 34:1389-1394.

Fancelli AL \& Dourado- Netto D (1999) Tecnologia da produção de milho. Piracicaba, FEALQ/ ESALQ/USP. 360p.

Falconer DS \& Mackay TFC (1996) Introduction to quantitative genetics. London, Longman Malaysia. 463p.

Lopes SJ, Dal"Col Lúcio A, Storck L, Damo HP, Brun B \& dos Santos VJ (2007) Relações de causas e efeito em espigas de milho relacionadas aos tipos de híbridos. Ciencia Rural, 37:15361542 .

Montgomery DC \& Peck EA (1981) Introduction to linear regression analysis. New York, John Wiley. 504p.

Scapin CA, Carvalho CGP \& Cruz CD (1995) Uma proposta de classificação dos coeficientes de variação para a cultura do mi1ho. Pesquisa Agropecuária Brasileira, 30:683-86
Stell RGD, Torrie JH \& Dickey DA (1997) Principles and procedures of statistics: a biometrical approach. $3^{\mathrm{a}}$ ed. New York, McGraw Hill Book. 666p.

Wright S (1921) Correlation and causation. Journal of Agricultural Research, Washington, 20:557-585. 